\title{
Products in environmental management systems: the role of auditors
}

\author{
Jonas Ammenberg and Erik Sundin
}

\section{Linköping University Post Print}

\section{Tweet}

N.B.: When citing this work, cite the original article.

Original Publication:

Jonas Ammenberg and Erik Sundin, Products in environmental management systems: the role of auditors, 2005, Journal of Cleaner Production, (13), 4, 417-431.

http://dx.doi.org/10.1016/j.jclepro.2003.12.006

Copyright: Elsevier

http://www.elsevier.com/

Postprint available at: Linköping University Electronic Press

http://urn.kb.se/resolve?urn=urn:nbn:se:liu:diva-13542 


\title{
Products in Environmental Management Systems: the Role of Auditors
}

Jonas Ammenberg* (a) and Erik Sundin (b)

a) Environmental Technique and Management

Dept. of Mechanical Engineering, Linköping University

S-581 83 Linköping, Sweden

(b) Production Systems

Dept. of Mechanical Engineering, Linköping University

S-581 83 Linköping, Sweden

\begin{abstract}
For standardised environmental management systems (EMS) to be environmentally effective tools, they should affect important environmental aspects related to flows of materials and energy, which for manufacturing companies are closely connected to their products. This paper presents how external environmental auditors interpret and apply important product-related requirements of ISO 14001 at manufacturing companies in Sweden.
\end{abstract}

The results indicate that the link between EMS and products is rather weak. Products are seldom regarded as significant environmental aspects and are therefore not within the main scope of many EMS, which are mainly focused on sites. However, all of the interviewed auditors require that some kind of environmental considerations be incorporated into product development, but these considerations are to large extent site oriented; how they are prioritized in relation to other factors such as economics and other customer priorities appears to be up to the companies.

The paper includes some recommendations to strengthen the role of products within the frames of standardised EMS.

Keywords: Design for Environment, DFE, Environmental Management Systems, EMS, ISO 14001, EMAS, Auditors

${ }^{*}$ Corresponding author: E-mail: jonam@ikp.liu.se, Tel: +46 132812 37, Fax: +46 13281101. 


\section{Introduction}

Several recent studies indicate that it may be fruitful for companies to integrate concepts of Design for Environment (DFE) into environmental management systems (EMS), although there are many important barriers to overcome [1]. DFE-thinking might enrich EMS by contributing with a life-cycle perspective, thereby helping the organisation to identify the most important flows of materials and energy upon which to focus. On an organisational level, this integration could induce better relations with stakeholders. At the same time, EMS may be useful to make corporate DFE efforts more permanent, i.e. lead to consistent and systematic DFE activities [ibid.].

Some empirical findings indicate that EMS certified in accordance with ISO 14001 lead to increased DFE activities [2-4], while other results are more pessimistic and bear witness to a weak link between EMS and DFE [1, 5, 6]. From this perspective, and as the number of standardised EMS increases rapidly around the world [7], it is of utmost importance to study what is required concerning product development for an ISO 14001 certified company. Karlsson [2] has pointed out external environmental auditors as important actors regarding the integration between EMS and DFE. In addition, Ammenberg et al. [8, cf. 9] argue that such auditors are key players concerning the connection between standardised EMS and environmental performance.

The relevance of this study rests upon four fundamental cornerstones. Firstly, the societal relevance of environmental issues is taken for granted. Secondly, the fact that standardised EMS are frequently used in many parts of the world makes them important to study from an environmental (and business) point of view. Thirdly, EMS certification is voluntary, the formulations in ISO 14001 leave a lot to be interpreted by its users and the results to large extent depend on the aspirations of the companies and the role of external environmental auditors. In addition, there is an ongoing debate concerning the trustworthiness of EMS, for example regarding regulatory relief for certified companies. Fourthly, for EMS to be effective and efficient environmental tools, these systems have to encompass and affect important aspects from flows of materials and energy. For a manufacturing firm, in general, many of these flows are directly linked to its products. Combining these four cornerstones, it seems important to illuminate how EMS are connected to DFE activities, thereby getting a better grip on how they affect the most relevant resource flows.

To illuminate these issues, this paper focuses on the role and perceptions of external environmental auditors, who could function both as a driver and as a barrier for the integration of DFE concepts ${ }^{1}$ into standardised EMS. This study is based on interviews conducted with auditors representing all nine Swedish certification bodies ${ }^{2}$. It presents how auditors interpret and apply the central requirements of ISO 14001 and their experiences and visions within this area, focusing on manufacturing companies. The paper consists of three main parts. Firstly, it is shown what ISO 14001 and the related standards include concerning products and product development. Secondly, the methodology for the interviews is described, including information on the central questions used. In the third and final section, the results are presented and discussed, which leads to some conclusions and recommendations concerning the future application of standardised EMS, focused on integration with corporate DFE activities.

\footnotetext{
${ }^{1}$ For an orientation concerning integration of EMS and DFE [see 1].

${ }^{2}$ I.e., firms accredited by the Swedish Board for Accreditation and Conformity Assessment, SWEDAC. Together these firms represent close to $100 \%$ of the EMS certification market in Sweden.
} 


\section{To what extent do requirements for standardised EMS encompass product development?}

It should be emphasised that the formulations in the ISO 14001 standard leave much to be interpreted by its users, e.g. companies and auditors [8]. Generously interpreted (from a DFE perspective), many requirements directly or indirectly affect product design [10]. In this section, the most relevant requirements concerning products in ISO $14001^{3}$ and the closest related standards in the ISO 14000 series $^{4}$ are presented and discussed. Table 1 shows a selection of important standard formulations.

It should be observed that only ISO 14001 of the chosen standards in the ISO 14000 series uses binding requirements in terms of what shall be done. The other standards only contain guidance and recommendations. Concluding from Table 1, there are many phrases, that directly or indirectly, affect products and product development. However, it is clear that product development is not emphasised in ISO 14001 and that most of the existing product-related requirements leave substantial room for interpretation. Nevertheless, based on common environmental facts (all flows of materials and energy are relevant from an environmental point of view and many important flows are connected to products/consumption [cf. 14, 15]), together with the wording presented in Table 1, most certified manufacturing companies (conducting product development) should have:

- product-related language in their environmental policy,

- identified issues in relation to products and product development processes as significant environmental aspects,

- environmental objectives and/or targets concerning products (otherwise product development must have been considered as an irrelevant function), and

- procedures to ensure that product development is handled within the EMS.

\footnotetext{
${ }^{3}$ Since ISO 14001 dominates the market for standardised EMS today [7] this standard will be emphasised in this paper. However, most of the reasoning and the results are valid for the European regulation EMAS [see 11], as well.

${ }^{4}$ The technical report ISO 14062 contributes with a lot of guidance on how to integrate environmental considerations into product development. However, it only contains very limited information on how to incorporate such efforts into EMS.
} 
Table 1. Important product-related formulations in the ISO 14000-series. The formulations are paraphrased to some extent.

\begin{tabular}{|c|c|c|c|}
\hline Formulation & Context & Standard & Section \\
\hline $\begin{array}{l}\text { Top management shall define environmental policy } \\
\text { and ensure that it is relevant to the nature, scale and } \\
\text { environmental impacts of its activities, products or } \\
\text { services. }\end{array}$ & $\begin{array}{l}\text { Requirements regarding an } \\
\text { organisation's environmental } \\
\text { policy. }\end{array}$ & $\begin{array}{l}\text { ISO } 14001 \\
{[10]}\end{array}$ & 4.2 \\
\hline $\begin{array}{l}\text { An environmental aspect is an element of an } \\
\text { organisation's activities, products or services that can } \\
\text { interact with the environment. }\end{array}$ & $\begin{array}{l}\text { Definition of the central term } \\
\text { "environmental aspect". }\end{array}$ & ISO 14001 & 3 \\
\hline $\begin{array}{l}\text { The organisation shall maintain procedures to identify } \\
\text { the environmental aspects of its activities, products } \\
\text { or services... } \\
\text { The organisation shall ensure that the aspects related } \\
\text { to the significant environmental impacts are } \\
\text { considered in setting environmental objectives. }\end{array}$ & $\begin{array}{l}\text { Description of procedures to } \\
\text { identify environmental aspects } \\
\text { and determine which are } \\
\text { significant. Also, a linkage } \\
\text { between significant environ- } \\
\text { mental aspects and objectives/ } \\
\text { targets should be made. }\end{array}$ & ISO 14001 & 4.3 .1 \\
\hline $\begin{array}{l}\text { The organisation shall establish and maintain } \\
\text { documented environmental objectives and targets at } \\
\text { each relevant function and level within the } \\
\text { organisation. }\end{array}$ & $\begin{array}{l}\text { Description of where in the } \\
\text { organisation environmental } \\
\text { objectives and targets shall be } \\
\text { established. }\end{array}$ & ISO 14001 & 4.3 .3 \\
\hline $\begin{array}{l}\text { If a project relates to new developments and new or } \\
\text { modified activities, products or services, } \\
\text { programme(s) shall be amended where relevant to } \\
\text { ensure that environmental management applies to } \\
\text { such projects. }\end{array}$ & $\begin{array}{l}\text { Requirements concerning } \\
\text { environmental programmes. }\end{array}$ & ISO 14001 & 4.3 .4 \\
\hline $\begin{array}{l}\text { For products this may address design, materials, } \\
\text { production processes, use and ultimate disposal. }\end{array}$ & $\begin{array}{l}\text { Recommendation on what an } \\
\text { environmental programme } \\
\text { could encompass. }\end{array}$ & ISO 14001 & $\begin{array}{l}\text { Annex A; } \\
\text { A.3.4 }\end{array}$ \\
\hline $\begin{array}{l}\text { Key principles for managers include to encourage } \\
\text { environmental planning throughout the product or } \\
\text { process life cycle. }\end{array}$ & $\begin{array}{l}\text { Key principles for managers } \\
\text { implementing or enhancing an } \\
\text { EMS. }\end{array}$ & $\begin{array}{l}\text { ISO } 14004 \\
{[12]}\end{array}$ & 0.1 \\
\hline $\begin{array}{l}\text { The policy can state commitments to minimise any } \\
\text { significant adverse environmental impacts of new } \\
\text { developments, embody life cycle thinking and } \\
\text { design products in such a way as to minimise their } \\
\text { environmental impacts in production, use and } \\
\text { disposal. }\end{array}$ & $\begin{array}{l}\text { Practical help on the } \\
\text { formulation of an environmental } \\
\text { policy. }\end{array}$ & ISO 14004 & 4.1 .4 \\
\hline $\begin{array}{l}\text { One of the issues to consider in identification of } \\
\text { environmental aspects concerns how any intended } \\
\text { changes or additions to products or services will } \\
\text { affect the environmental aspects and their impacts. }\end{array}$ & $\begin{array}{l}\text { Guidance on identification of } \\
\text { environmental aspects and } \\
\text { evaluation of associated } \\
\text { environmental impacts. }\end{array}$ & ISO 14004 & 4.2 .2 \\
\hline $\begin{array}{l}\text { Objectives can include commitments to design } \\
\text { products to minimise their environmental impact in } \\
\text { production, use and disposal. }\end{array}$ & $\begin{array}{l}\text { Practical help on the } \\
\text { establishment of environmental } \\
\text { objectives and targets. }\end{array}$ & ISO 14004 & 4.2 .5 \\
\hline $\begin{array}{l}\text { The organisation should consider activities to prevent } \\
\text { pollution and conserve resources in new products. }\end{array}$ & $\begin{array}{l}\text { Practical help on operational } \\
\text { control. }\end{array}$ & ISO 14004 & 4.3.3.3 \\
\hline $\begin{array}{l}\text { Where multiple activities or physical facilities } \\
\text { produce or provide a particular product or service, } \\
\text { the organisation should take them into account when } \\
\text { evaluating environmental performance. }\end{array}$ & $\begin{array}{l}\text { How to select Operational } \\
\text { Performance Indicators (OPIs). }\end{array}$ & $\begin{array}{l}\text { ISO } 14031 \\
{[13]}\end{array}$ & 3.2 .2 .3 \\
\hline $\begin{array}{l}\text { An organisation may select its indicators by } \\
\text { considering the inputs and outputs associated with a } \\
\text { particular product, and the significant environmental } \\
\text { aspects and impacts at any stage of a product's life } \\
\text { cycle. }\end{array}$ & $\begin{array}{l}\text { Guidance on how to use a life } \\
\text { cycle based approach when } \\
\text { establishing indicators. }\end{array}$ & ISO 14031 & $\begin{array}{l}\text { Annex A } \\
\text { A.3.2.3 }\end{array}$ \\
\hline
\end{tabular}




\section{Methodology}

The study was conducted through interviews with nine auditors, one from each of the nine Swedish certification bodies. These firms cover an absolutely dominant part of the EMS certification in Sweden, but there are also some foreign companies on this market. In most cases, the selected auditors represented the certification body in a joint group, where common topics of interest to the certification bodies are discussed ${ }^{5}$ and common practices are developed, e.g. issues concerning interpretation of central requirements of ISO 14001. In addition, many of them are responsible for the environmental certification activities within their firms, which means that they are well informed about the work of many other auditors and that they probably are regarded as successful within their line of business.

To be able to compare the answers without steering the interviewees too much, semi-structured interviews were used [see 16]. This means that some main questions, presented and theoretically motivated later in this section, were prepared in advance and directed at all auditors. These prepared questions served as "signposts" to point out the direction for the following conversation. In addition, many related questions were asked to further investigate the opinion and practice of the interviewees. These questions were not prepared in advance, but depended on the answers given. For the interviewer to be able to listen carefully, focus on the answers and formulate appropriate related questions, the interviews were recorded on tape. This may have resulted in some tension for the interviewees. However, every interviewed auditor was promised full anonymity, both individually and concerning his or her company and the audited firms. This, hopefully, lessened any anxiety. An absolute majority of the auditors appeared to be relaxed during these interviews. It was emphasised that the auditors should focus on manufacturing companies. It was also stressed that by "products" we meant the physical products produced by the manufacturing firms focused on, and by "product development", we meant the formal organisational procedures and processes which were intended to steer the product design and the production.

After all interviews had been conducted, the recorded answers were analysed. First, they were transcribed and then a process to summarize the answers began. They were characterized and classified - a process involving interpretation and a search for keywords. This process was designed to extract the core points of the answers and for dividing them into several more or less separate groups, i.e. they were transformed to fit a more quantitative analysis.

During the whole interview and interpretation process, obviously, subjectivity is a problem [see 17]. By being aware of that fact, the consequences of this problem have hopefully been restricted. For example, the introduction to each interview and the questions have been formulated in such a way as to avoid leading the interviewees. Further, the questions were organised according to level of detail. Within each area of interest, the respondents were first asked comprehensive questions, followed by questions on a more detailed level. As a result, the risk of leading the respondents has been reduced. For the same reasons, the interviewers tried to react neutrally to the answers given, thereby trying not to signal if any answers were preferred or disliked. During the phase of interpretation, characterization and classification of the answers, the authors tried to understand the central opinions of the interviewees and thereby to summarize the answers as correctly as possible, which of course is a difficult task and a weakness of the

\footnotetext{
${ }^{5}$ To select auditors from this special group was a conscious choice in order to get successful auditors with extensive experience.
} 
methodology. However, the standardised terminology concerning EMS makes it easier to communicate on these issues. In addition, the interviewers to some extent summarized their impressions during the interviews and asked the respondents if they had been correctly understood, which facilitated the interpretation process. Naturally, what was selected in this process and presented as results depended on the aim of the study.

The results show different ways of acting and motives to do so and may to some extent show what is most common. However, although the auditors are very experienced and have a great overview of environmental audits, the low number of interviewees means that the results only give indications.

\section{Prepared questions for the interviews}

This section serves as a theoretically based motivation for the questions directed to the auditors. Some questions that constituted the base for the interviews are presented in a condensed way, i.e. they have been summarized, which means that these questions were represented by several more detailed questions during the interviews. The questions were chosen to illuminate the integration of EMS and DFE in corporate practice, by focusing on the most relevant issues in relation to environmental impacts.

Since the ISO 14001 standard is not very specific on if and how to incorporate product issues into an EMS, the authors of this paper sought to ascertain the extent, how and where within the EMS the audited companies handle product-related activities. One goal was to illuminate the relation between products/product development and central EMS terms [cf. 18], such as “environmental aspect”, “significant environmental aspect”, “environmental policy”, "environmental target”, "environmental programme” and "continual environmental improvement". Accordingly, the auditors were asked": To what extent are products and product development normally handled within or affected by the companies' EMS? and What is the relation between manufacturing companies' products/product development and the terms environmental aspect, significant environmental aspect, environmental policy, environmental objectives and targets and environmental programmes?

To receive more specific answers concerning product development, the following questions were used: Do you require environmental criteria to be included in the product development procedures? and, in case of a positive answer, Do these requirements concern specific sites or are also other parts of the products' life cycles involved? and Do the requirements you put on the companies vary dependent on the size of the companies?

A drawback of EMS that is sometimes mentioned in the literature is that they often are, or at least have been, directed at site levels $[6,19,20]$. Very little is said in the standards' texts concerning the scope of an EMS. For clarification on the practical application of these issues, the respondents were asked: What scope of EMS is normally used?, How is transportation normally handled?, and To what extent are suppliers and customers affected by the EMS?

\footnotetext{
${ }^{6}$ To remind the respondent to talk about their own experience and manufacturing companies, the phrase "based on experiences from the manufacturing companies you are auditing”, was often added to the questions listed in this paper.
} 
Continual improvement of environmental performance is a key commitment for an organisation using an EMS $[10,18]$. However, it is the authors' experience that what goes under the term "environmental performance" varies to a great extent. Therefore it seemed urgent to better understand how the requirement for continual improvement is applied in relation to products and product development. For this purpose, the following questions were directed at the respondents: What is environmental performance to you, i.e. what is it that the firms are supposed to improve?, What is the relation between the requirement for continual improvement and the companies' products/product development?, Are improvements allowed to occur at different places in the product life cycle (e.g. within the site or at a customer's site)? Further, there is an ongoing debate concerning to what extent EMS support or prevent innovations or environmental progress. On the one hand, it has been suggested that the striving for continual improvement supports innovations, on the other that companies tend to save improvements to ensure conformance in the future, which would prevent the improvement rate. To illuminate these issues, the following question was formulated: Do you believe that EMS function as a driver and/or barrier concerning innovation?

Research findings show that it is important to engage the right persons, e.g. cross-functional teams, in DFE programmes to make them successful [cf. 2, 6]. Consequently, the authors sought to obtain insight into the auditors' experiences concerning the kind of staff that is involved in companies' product development processes, which motivates the question: Do companies manage to engage the right persons in products and product development through their EMS?

Finally, to summarize the auditors' experiences concerning the relation between standardised EMS and products/product development, and to understand their thoughts and visions on how to improve this relation, the following questions were used: How would you grade the connection between EMS and product development, choosing from the categories; very weak, weak, middling, strong or very strong?, How would you judge your possibilities to affect the connection between EMS and DFE activities? and What is important to strengthen this connection?

\section{Results}

\section{Auditors' experience}

Eight of nine interviewed auditors have extensive experience concerning EMS at Swedish manufacturing firms. The ninth auditor had only audited three manufacturing companies, but could in addition to information from these companies contribute with useful facts due to experiences from colleagues and several relevant assignments as a consultant. Besides the common auditing activities, at least five of the interviewees are responsible for the environmental auditing within their firms, which means that they get insight from many other auditors and manufacturing enterprises.

All of the respondents have experiences from small and medium-sized enterprises, while only a few of them have large companies as customers.

\section{Environmental aspects and products}

EMS are built around the environmental aspects. Every certified company must identify its environmental aspects (see definition in Table 1) and then assess them to determine which aspects are significant. The main aim of an EMS is to steer and control these significant 
environmental aspects. Thus these identification and assessment processes are extremely important, since they determine the focus of EMS. When asking the auditors about the relation between environmental aspects and products, the answers showed that product-related environmental aspects exist on many different levels. On the overall level, there exist environmental aspects that concern the whole product as such, which means that the manufactured products, or issues directly connected to these products, are regarded as environmental aspects. Relevant issues mentioned are, for example, the products' recyclability and energy consumption during the use phase. On a more detailed level, product-related aspects such as usage of raw materials, energy, process chemicals, transportation, etc. are defined as environmental aspects ${ }^{7}$. The scope, or focus, of these aspects varies along the product life cycle. This means that aspects formulated equally can have a different focus. For example, concerning chemicals one firm may focus on effluents at their site while another firm investigates the impacts of the supplier.

According to a majority of the auditors, it is common that companies have not regarded or included issues concerning their whole products as environmental aspects before the first meeting with the auditors. They claimed unanimously that a dominant part of the manufacturing companies, in the beginning of their EMS process, focuses on site-specific aspects. However, this site-specific scope to some extent includes goods and energy that are often declared as environmental aspects. This means that the EMS often have links backward in the supply chain ${ }^{8}$.

So far, the auditors seem to agree. But concerning to what extent products are required to be included in an EMS for these systems to be approved and certified, the opinions differ. Two auditors approve EMS where the product issues are not included among the environmental aspects, while the remaining auditors require that product issues are regarded as environmental aspects (see Figure 1). One auditor from the first group added that companies do not normally

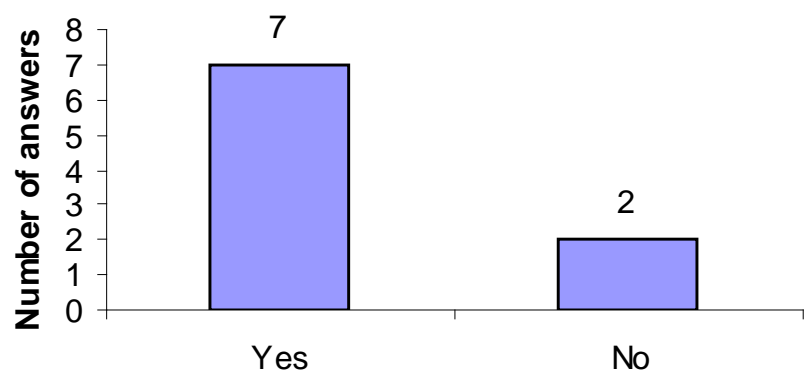

relate the amount of resources used to the manufactured products.

Figure 1. The answers to the question: Do products have to be included in, or covered by, the 'gross-list' of environmental aspects?

The experiences concerning to what extent product issues are judged as significant environmental aspects also vary. Six auditors stated that product issues seldom are assessed as significant. Two within this group added that it would be annoying for the companies if their

\footnotetext{
${ }^{7}$ These aspects were normally not referred to as product-related aspects by the auditors, but were mentioned in relation to more specific questions regarding the view of resources.

${ }^{8}$ Where the supply chain concerns all steps from material extraction to end-of-life treatment.
} 
products were classified as significant environmental aspects. One auditor said that to what extent products are judged as significant varies depending on the product types and EMS construction and another declared that products are often judged as significant ${ }^{9}$ (see Figure 2). Concerning their requirements on these issues, many auditors referred to the companies' assessment of environmental aspects, saying that it is up to the enterprises to determine which aspects are most important. About one-half of the respondents stated that they review the companies' assessment methods to see if they are reasonable. Moreover, they declared that if these methods are found reasonable, they cannot argue about the results, i.e. they may not require that product issues are considered as significant environmental aspects. One auditor stated that the aspects are often assessed in such ways that site-oriented aspects are prioritized.

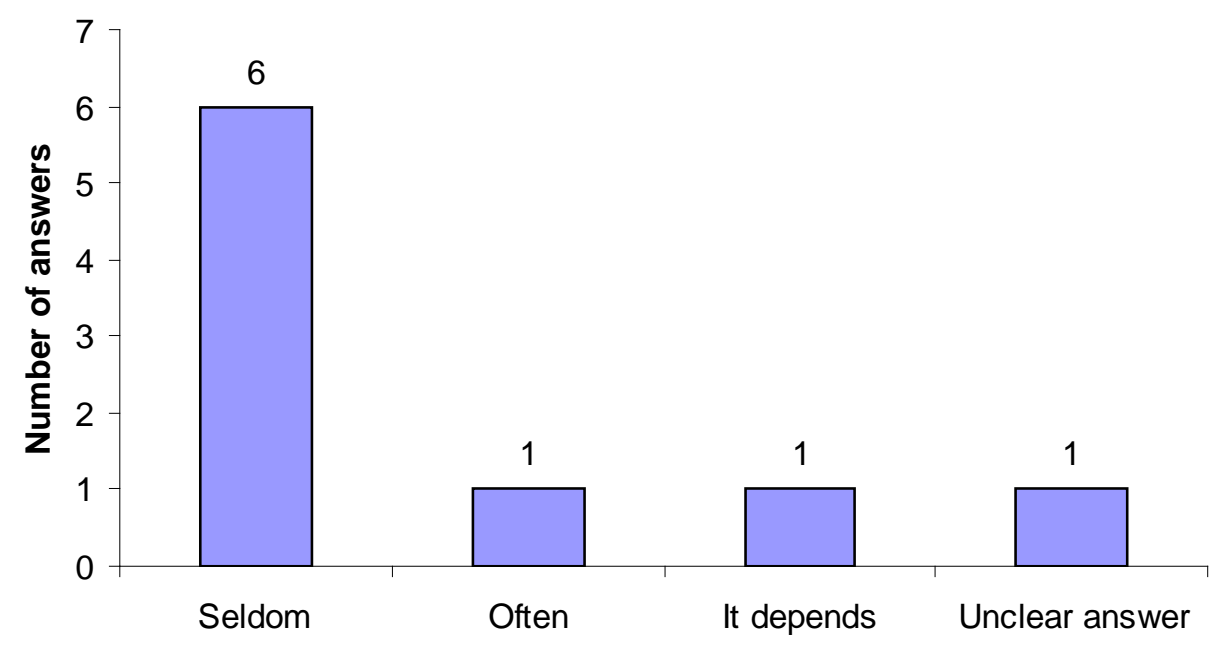

Figure 2. The answers to the question: How often are the whole products, or issues directly related to them, judged as significant environmental aspects?

According to the standard text ${ }^{10}$, which aspects are significant depends on the possibilities to control and influence. Four of the auditors mentioned that they often face companies that argue that they have too little influence on their products. Examples when this is valid are when customers manage the specification of requirements in detail and when goods bought at one site have to follow a master agreement within a group. The auditors interpret and apply the text concerning possibilities to control and influence very differently. Some of the interviewees try to convince the companies that it should be control or influence, which means that an aspect may be significant even though the company representatives do not believe they can influence it. Others, with the same intention, say that the companies can always influence. They, in some sense, regard try to influence and influence as equal, meaning that companies can influence their relevant stakeholders even if it does not result in direct physical changes. It is enough if their efforts, for instance, affect the mind of an actor, which might result in changed behaviour later on. Still others seem to accept that product-related aspects are not classified as significant due to limited possibilities to influence.

\footnotetext{
${ }^{9}$ For some questions not all answers were clear. In these cases the unclear answers have been left out, which means that the sum of answers is less than nine.

${ }^{10}$ ISO 14001, section 4.3.1.
} 
The possibilities to handle product-related issues are closely related to knowledge. Four of the respondents mentioned that many firms have problems due to lack of knowledge. They stated that companies often lack sufficient competence to handle the environmental issues related to products. Further on, many of them claimed that available tools are too complex and time demanding. One auditor thought that legal requirements direct companies' environmental efforts towards site perspectives and therefore indirectly lead to lower priority for the life cycle perspective. The auditor in question continued by saying that auditors as well as companies and consultants, at least until now, have been focused on site-specific activities. Also, supported by another auditor, he ${ }^{11}$ described a process of development where companies that implemented EMS several years ago now are approaching product-related issues.

\section{Environmental policies and products}

Concerning to what extent manufacturing companies' environmental policies include productrelated formulations, a majority of the auditors say that policies have a tendency to be too generally formulated. They want the companies to be more specific. A few of the auditors mentioned that if some product issues are judged as significant environmental aspects, then the environmental policy formulations should address them. According to the auditors' answers, the link between products and policy formulations must be characterized as weak. Probably this is a consequence of product issues seldom being classified as significant.

\section{Environmental objectives, targets and products}

Five of the interviewees stated that environmental objectives and targets seldom are directly connected to products. A few of the auditors mentioned that there could be targets aimed to reduce the amounts of energy and raw material. Here as well, the outcome was coupled to the assessment of the environmental aspects.

\section{Environmental programmes and products}

Regarding environmental programmes, where the standard ${ }^{12}$ specifies that they should cover new developments and new or modified products, an absolute majority of the auditors argue that they are strongly linked to the targets and thereby include products to the same extent as the objectives and targets. Many of them also declared that there often exist instructions, including checklists, for specific projects related to product development. However, these instructions are not necessarily closely connected to environmental management programmes. Two of the auditors specifically stressed that when products are developed, the staff has to analyse the changes and establish if any new environmental aspects have occurred.

\section{Environmental considerations in product development}

A majority of the auditors require that environmental considerations are incorporated into the product development process. One of these auditors emphasised that it is up to the company to decide if these considerations are to be prioritized in comparison with other product criteria. Three of the respondents said that they cannot find support in the standard for such requirements. Instead they bring this question up as a point for discussion (see Figure 3).

\footnotetext{
${ }^{11}$ In this paper "he" is used for both males and females, to ensure the respondents' anonymity.

${ }^{12}$ ISO 14001, 4.3.4.
} 


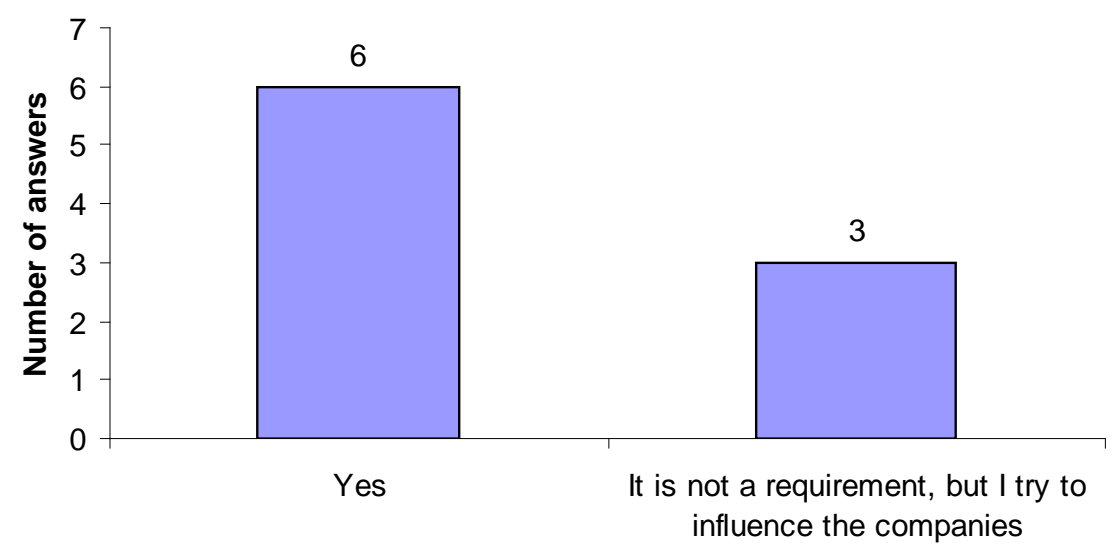

Figure 3. The answers to the question: Do you require that manufacturing companies include environmental considerations in the product development process?

The character of the environmental considerations seems to vary. Some auditors mentioned that simple checklists are used in the design phase, e.g. to avoid using certain chemicals. Many of the respondents stated that Volvo's 'black and grey lists', including hazardous chemicals, are used frequently. A few of the auditors mentioned that companies having quality systems should add environmental checkpoints where relevant in these systems. They also mentioned that quality systems facilitate the establishment of procedures that include environmental considerations in product design.

The scope of these environmental considerations differs somewhat, according to the auditors. Three of the respondents claimed that the checkpoints or criteria used are focused on the manufacturing facility. On the contrary, another two said that the products and their life cycles must be considered. Furthermore, one auditor said that the scope depends on companies' available resources for this task (see Figure 4).

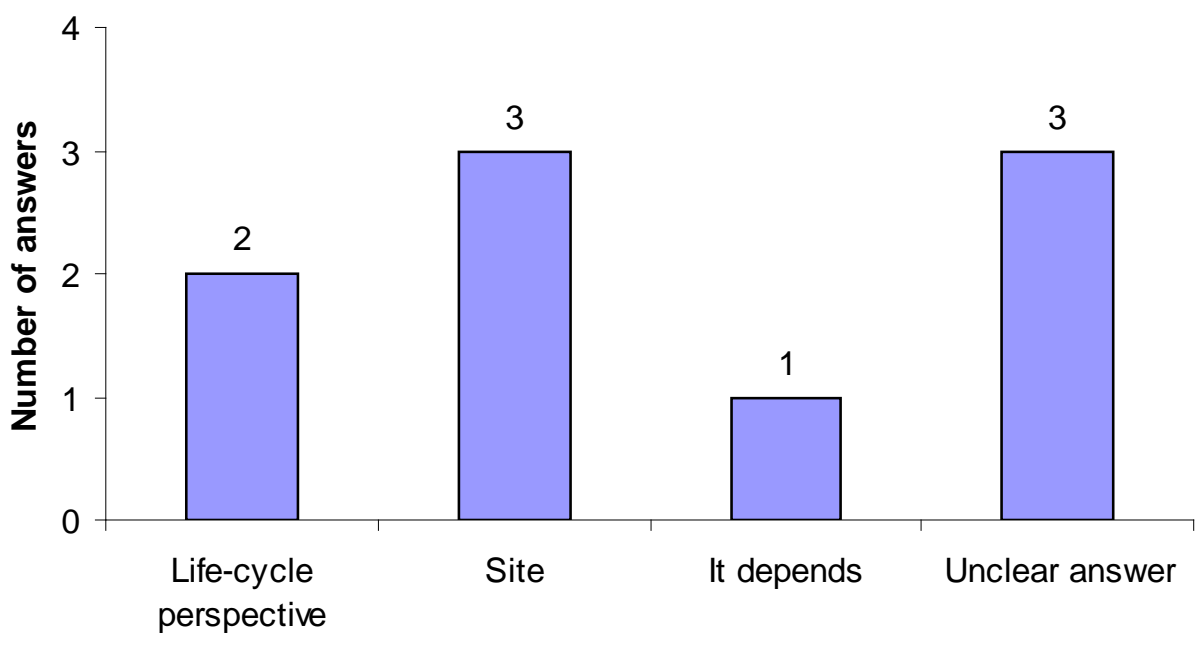

Figure 4. The answers to the question: What is the scope of these environmental considerations? 
Concerning whether the size of a company affects the auditors' requirements, four of the respondents stated that the requirements are the same irrespective of size, although their applications differ depending on company size. Another four interviewees declared a principally different view, since they said that the requirements vary with the size of the audited firms.

Whether EMS involve proper staff categories when it comes to product design is an interesting question. It is noteworthy that many auditors had some initial problems understanding the questions in this area of interest. In some cases it appeared as if these questions and ways of thinking were a bit unfamiliar. The answers given cover a wide spectrum of opinions. On the one side, many auditors mentioned problems due to EMS steered by former quality managers and due to problems in co-operating with and integrating unmotivated designers (engineers) who dislike environmental considerations, for example, since they limit their degrees of design freedom. At least five of the auditors recognised this situation as quite common but emphasised that it varies dependent on factors such as knowledge, culture, motivation, etc. On the other side, one auditor stated that if the right persons are not involved when he first meets with a company, he requires changes. This respondent, contrary to many other auditors, claimed that designers often consider it natural to include environmental issues, since they are linked to costs. A sixth auditor said that within a small firm the same person handles many relevant issues, so there is no problem concerning integration. Two additional comments should be mentioned. In line with the last answer, one interviewee claimed that when environmental, quality and research matters are handled by the same person, the integration works fine. Another auditor was of the opinion that companies using both an environmental and a quality system often have advanced further than other companies concerning DFE activities.

\section{The scope of EMS}

According to six of the respondents, companies' environmental reviews are to large extent focused on their own facilities. One auditor requires a wider approach. A seventh interviewee argued that the scope of the reviews should depend on the firms' possibilities to influence. The remaining auditor said that he did not know, since he does not always receive the reviews (see Figure 5).

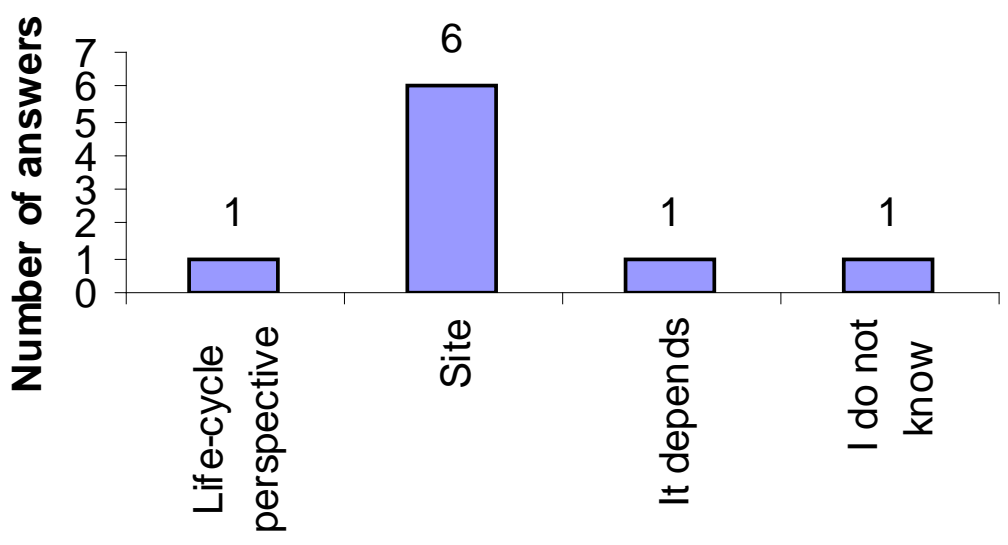

Figure 5. The answers to the question: What scope do the initial environmental reviews have? 
Regarding the complete EMS, five of the auditors stated that EMS are often focused on a specific site, one of them added that suppliers are included as well. As a clarifying comment, one of these persons said that what is required concerning the scope is a kind of grey area where the requirements are adapted in accordance with the companies' ambitions. One interviewee said that the main focus is on the site, but emphasised that there are other relevant parts of the EMS that include other phases of the life cycle. Two of the respondents said that they allow a narrow, facility-oriented scope in the beginning and then add tougher requirements later on (see Figure 6). One of these auditors motivated this way of acting by saying that it is psychologically sound for the companies to get a good grip of the environmental issues within their sites, before widening the scope.

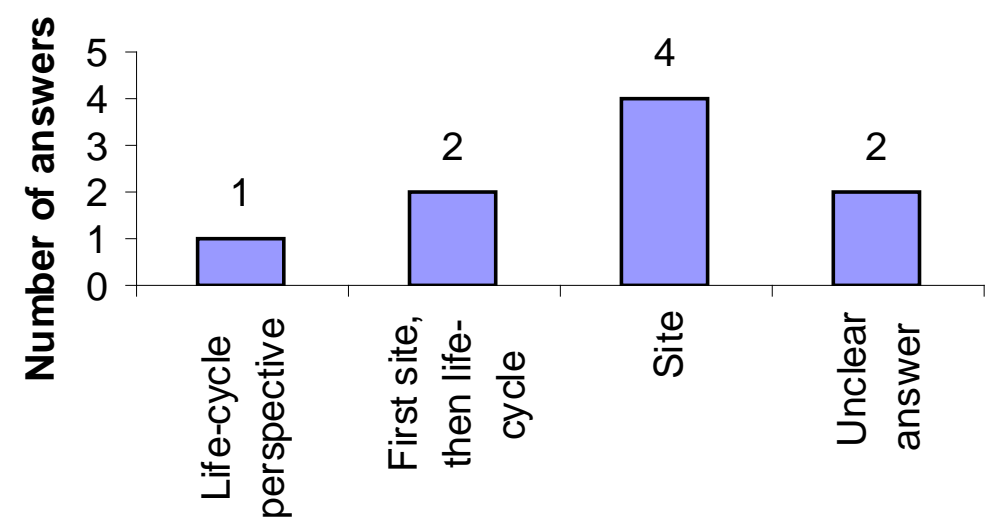

Figure 6. The answers to the question: What scope does the complete EMS have?

All but one auditor stated that transportation is covered by EMS. A few of them added that it is sometimes difficult to measure aspects of transportation and formulate environmental targets addressing them. One auditor within this group declared that transportation occasionally is difficult to influence. The remaining auditor said that to what extent transportation is included within the EMS depends on who is responsible for it. He continued by saying that if a customer collects the products, then the manufacturing company should not deal with the transportation.

All of the auditors declared that requirements shall be communicated to suppliers ${ }^{13}$. However, an absolute majority characterizes these requirements as rather trivial, since these requirements are often in the form of a kind of checklist or a questionnaire. The following summarized statements illustrate the opinions of most of the auditors;

- $\quad$ The companies approve suppliers even if they are not certified. Then they just tick some other boxes and are approved anyway...

- Often the companies ask if the suppliers have an EMS, or at least an environmental policy. Then they try to communicate that they have some kind of requirements, of which they themselves have a rather fuzzy understanding ...

- $\quad$ The firms often add questions to existing ones within their quality systems. They ask questions like; Do you have an EMS? Do you have an environmental policy? Do you establish environmental objectives? If all questions are answered positively, the supplier gets

\footnotetext{
${ }^{13}$ See ISO 14001, section 4.4.6.
} 
three points and is accepted. If a supplier only gets one point, it is given a chance to improve and is accepted anyway...

- Companies often send out questionnaires and hope they will receive some answers...

Some of the auditors declared that the standard's ${ }^{14}$ intention is not for the companies to assess the environmental work of their suppliers, but to investigate relevant issues concerning goods bought from them. They indicate that they strive to alter the enterprises' behaviour to move beyond the simple questionnaires.

Environmental information, e.g. advice on usage and end-of-life treatment, is seldom communicated to the customers according to most of the auditors. Two of the respondents claimed that this is due to lack of knowledge. One of them assigns these competence problems to the manufacturing companies, while the other refers to incompetent customers, which was stated to "make this kind of communication meaningless". It was mentioned by one of the auditors that the customers are commonly informed about how to handle the packaging materials. Some auditors emphasised that market investigations, including environmental issues, are important in order to get knowledge of stakeholder opinions. These kinds of mappings are used to decide what to prioritize.

Some of the auditors stated that the companies they get in touch with have a "lack of knowledge concerning environmental issues outside their gates”.

\section{Continual improvements}

Regarding the key commitment to continually improve, the auditors were asked what the companies are supposed to improve. Five of the interviewees answered that some improvements must be of an operational character, of which two emphasised that such improvements imply a reduced environmental impact. One-third approve progress solely of a management character ${ }^{15}$. However, one of them added that the improvements must be linked to the significant environmental aspects, while another said that it is up to the company to decide the character of the progress. The remaining auditor said that he had no clear opinion on these issues (see Figure 7). One of the auditors said that in Sweden, contrary to the application in some other countries, we have agreed that it is not enough to just improve the system, environmental performance has to improve. ${ }^{16}$

\footnotetext{
${ }^{14}$ ISO 14001.

${ }^{15}$ For definitions of operational and management indicators, see ISO 14031 [13].

${ }^{16}$ When later asked to clarify this statement, the auditor said that abroad it is sometimes approved to improve just your formulations. He continued by saying that in Sweden we demand that environmental performance is improved, which includes both operational and management performance.
} 


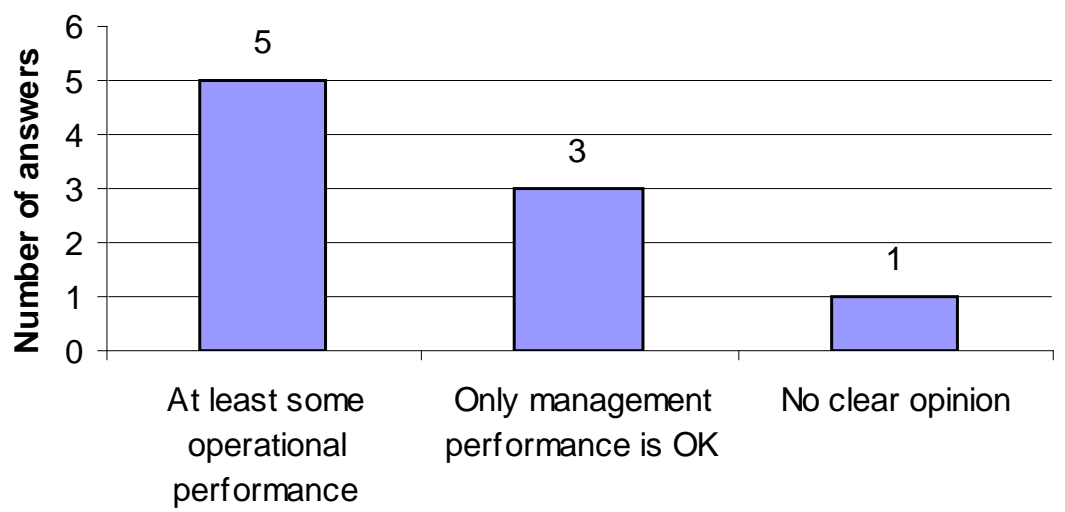

Figure 7. The answers to the question: What kind of improvements are to be reached? Concerning the relation between the key commitment and products, four respondents declared that these improvements seldom are directly linked to products. One of them said that improvements more often involve emissions, transportation, energy or waste ${ }^{17}$. Another quartet stated that products may be included when striving for continual improvements. One of them added that to what extent this is the case, depends on the assessment of the environmental aspects. Another auditor said that he requires good control over every significant environmental aspect, so that the development can easily be traced, which facilitates judgements of the requirement for continual improvements. It was also mentioned that the process of continual improvements in some cases is regulated through legislation (legal permits). One auditor seemed to find it very difficult to control this requirement. The person in question said that he as an auditor does not always have a good understanding of these improvements and that it is hard to analyse changes without a complete life cycle analysis.

All of the respondents said that it does not matter where within the life cycle improvements are reached, i.e. improvements are approved independent of where they occur within the supply chain. Nevertheless, one auditor highlighted the fact that the standard is not clear on these issues.

When asked how new products are incorporated into the process of improving and if improvements concern a kind of total performance, many auditors were a bit hesitant. A majority said that a lot of the environmental performance is measured as ratios, which means that, for example, the amounts of raw materials are divided by the turnover, the number of products or the number of man-hours [cf. eco-efficiency 21, 22]. A few of the interviewees clearly declared that they advise companies to avoid total numbers in their environmental performance, as this would prevent expansion. Many auditors stated that changes in flows of resources (materials and energy) are related to business benefits, which means that environmental deterioration may be compensated by business improvements. One statement can be used to illustrate this: "Everything is related to business performance and economic factors. We can only require that the company show us how they have prioritized and who is deciding on these issues”. Several auditors manifested previous results [see 8] by saying that continual improvements are judged based on firms' environmental targets. A few statements have been selected to show the variation in opinions on continual improvements:

\footnotetext{
${ }^{17}$ That is, not calculated or regarded in relation to products.
} 
- "Companies do not get a value $X$ that indicates their environmental performance when certified, which they are then supposed to improve. It does not work that way".

- "Whenever I notice a dip concerning environmental indicators I ask why this dip has occurred".

- "My impression is that you as an auditor should be happy if anything is measured at all. Then you have to stick to these measurements, be grateful for them measuring something and try to notice any trends".

- "As a company, you are not allowed only to select the small improvements. You have to have reasons to drop large improvements, i.e. reasons approved by the standard".

- "Luckily, much within the environmental sphere is connected to economic factors. If you increase the use of resources [authors' comment: such as materials and energy] you also increase your cost".

Concerning whether companies tend to save improvements to ensure future continual improvements, seven auditors gave a clear and straight answer, see Figure 8. Three of them said that companies sometimes tend to save improvements, i.e. improve at a lower rate than possible to save progress for the future. Four did not believe that companies save improvements. However, one of them added that it is possible that small enterprises save improvements, since they more often have problems finding new areas of improvement. Another auditor within this group said that companies with uncomplicated production or wholesalers ${ }^{18}$ have problems reaching improvements.

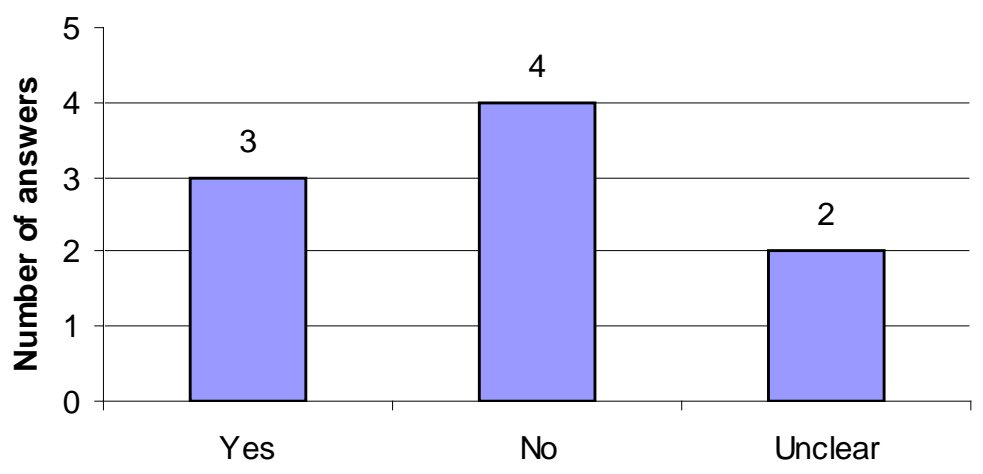

Figure 8. The answers to the question: Do you believe that companies sometimes save improvements to ensure future progress?

The two remaining auditors delivered answers that must be characterized as a bit unclear and paradoxical. The first of them said that he did not believe that companies save improvements, but then added that if they do it is because they want to be sure to reach their targets. The second said that if this is the case, it depends on a lack of fantasy, continuing by saying that he had never met companies that did not have new areas to improve. He finished by adding that "if a company suggests a $10 \%$ improvement instead of a 50\% improvement, I cannot argue about that”.

When asked to grade the connection between EMS and products/product development, choosing from the categories very weak, weak, middling, strong or very strong, the interviewees responded as shown in Figure 9.

\footnotetext{
${ }^{18}$ It was emphasised by the authors, before the interviews, that wholesalers are not regarded as manufacturing firms.
} 


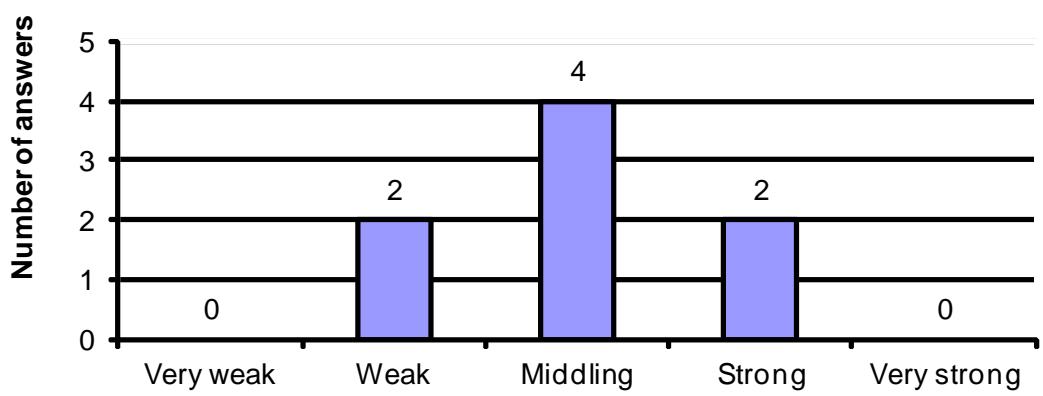

Figure 9. Results that show how the auditors have graded the connection between EMS and products/product development.

Two of the auditors thought that the link was weak, while four stated that the connection was middling. Another two graded this connection as strong, of which both indicated that they have a good support in the standard ${ }^{19}$ to require a strong link between EMS and DFE. The remaining auditor replied that the strength of the connection depends on the importance of the manufactured products and did not want to give a general answer.

The role of auditors

The auditors were asked to grade their possibilities to influence the audited firms so that products are better incorporated into the EMS. As shown in Figure 10, a majority answered that they have great possibilities to influence the companies, while three auditors were a bit more neutral and said that they can have an influence. One of these auditors added that as an auditor you by definition are not supposed influence, but in reality it works like a kind of benchmarking where knowledge, via the auditors, is transferred between companies ${ }^{20}$. The remaining respondent said that he should not influence the companies, but only make sure that they comply with the standard's requirements.

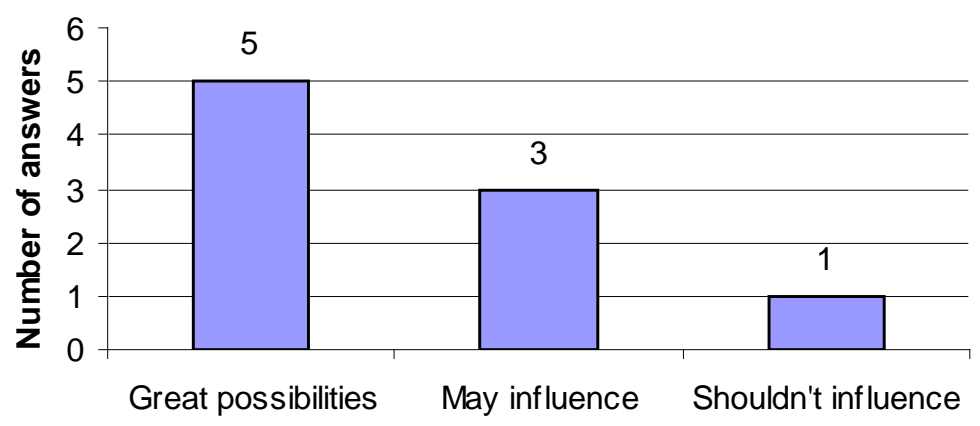

Figure 10. Results that show how the auditors have graded their possibilities to influence the audited firms so that products are better incorporated into the EMS.

\footnotetext{
${ }^{19}$ ISO 14001.

${ }^{20}$ It should be observed that many auditors, during discussions related to these issues, indicated that this kind of information is only allowed to be transformed between different branches, but not within the same branch, due to reasons concerning competition.
} 
Regarding the role as a consultant, one auditor stated that companies today want to gain more from the auditing activities. They require an increased value and want to have more than just notes concerning nonconformance, which leads to a complicated situation. He continued by saying that on the one hand the auditors have to fulfil the companies' wishes, on the other hand they should not become consultants and audit their own suggestions. Finally, he stated that he had heard that the other certification bodies act similarly. This auditor and a few others as well indicated that they do not want to provide finished solutions, but try to affect the companies' way of thinking.

One interviewee mentioned that when companies are blind to defects within their site, the auditors have a very important role in helping them to find new areas to deal with. A few of the respondents described their roles as those of a discussion partner or a 'sounding board'.

\section{Comparison of the auditors}

To illuminate how the auditors' opinions vary and to verify that some of them almost consistently pose tougher requirements than others, a simple test was conducted. For five important areas the answers were compared and classified into one of three groups, in accordance with which is more preferable from an environmental point of view. The five areas concerned (the three groups are within parenthesis):

- To what extent products are considered as significant environmental aspects (often; it depends, seldom)

- If environmental considerations are required in product development (yes; I try to influence; no)

- What these requirements encompass (life cycle; it depends; site)

- The scope of EMS (site + other important parts; first site, then life cycle; site)

- What kind of improvements are required to be reached (operational; only management OK; don't know)

In addition to the three groups, a fourth was added for unclear answers. To be able to display the distribution of the answers, each group was given a score to indicate how preferable it was.

Answers within the most preferable group were given five points, within the middle group three points, while the answers categorised in the third group received one point. Unclear answers were also given one point. The results showed that one auditor's answers were classified in the best group, i.e. the group including the most preferable answers from an environmental point of view, for all five questions (see Figure 11, where each of the nine auditors has been assigned a letter). He and another auditor appear generally to pose significantly tougher requirements than the others do. At the other extreme, two of the respondents seem to accept EMS that are very weakly linked to products. The remaining auditors are spread quite equally between these two groups of auditors. Only the highest ranked auditor was within the same category for all the questions. All the others' opinions swung between the different groups, i.e. from preferable opinions to standpoints less advantageous for the environment. 


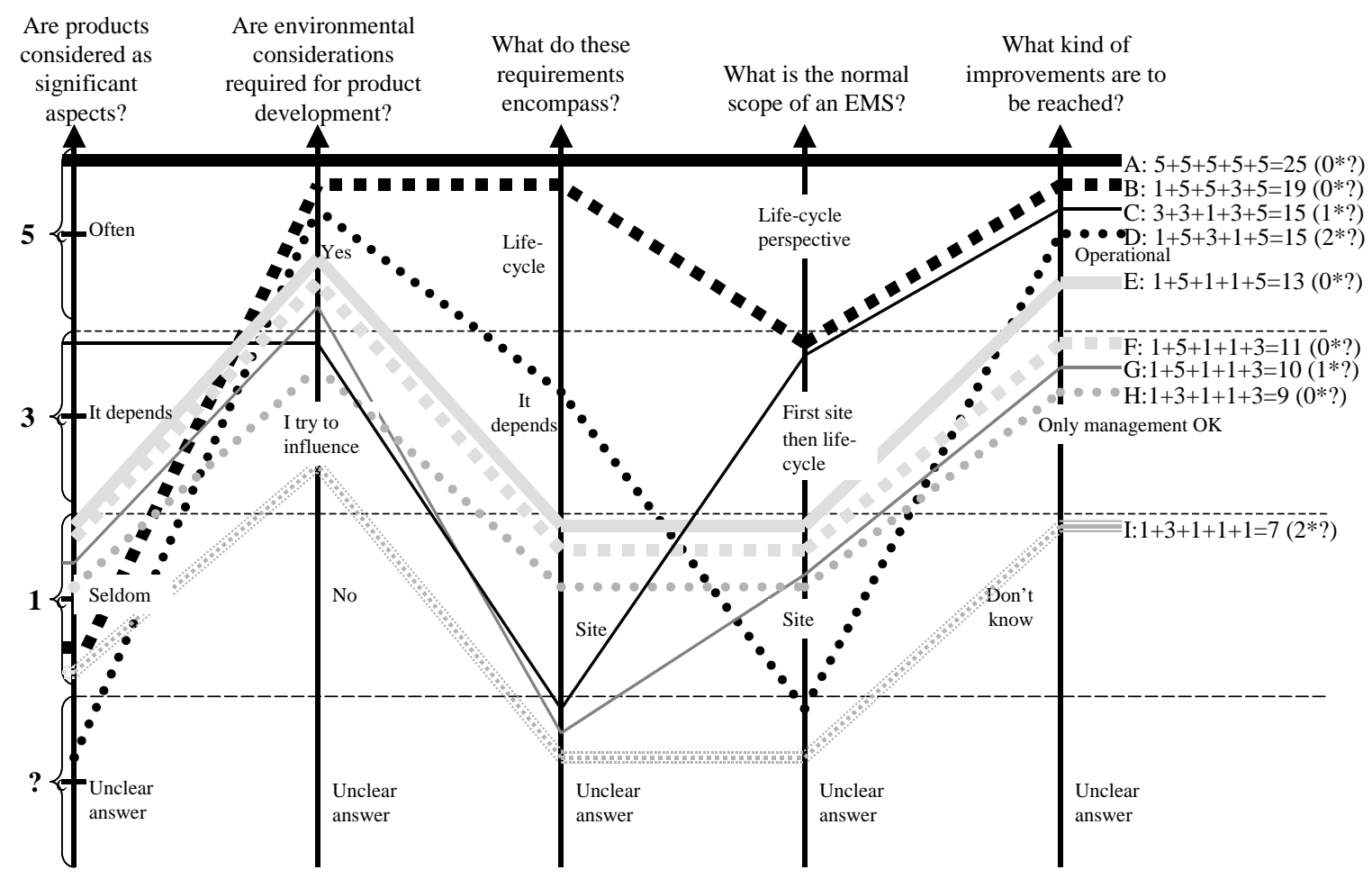

Figure 11. Distribution of the answers to five important questions. Each line corresponds to one auditor. The sum for each auditor's answers is explained in the upper right corner. Unclear answers (the lowest row, indicated with a "?") received one point.

\section{Future prospects and wishes}

About one-half of the auditors desire revisions in the standard' ${ }^{21}$ text. A few of them wanted stronger requirements regarding products, while others seem to wish for clarifying changes. Four of the respondents are satisfied with the standard's existing formulations on these issues. One auditor, within the first group, suggested a special section in the standard where product-related issues would be covered. He, as well as another auditor, proposed adaptations that would make the 14001 standard more similar to ISO 9001 concerning these issues.

Regarding how to strengthen the connection between EMS and DFE, besides changing the standard and the systems for its application, the auditors had many suggestions. Almost all of them emphasised the importance of customer demands. This included consumers as well as business customers. Large multinational companies, like IKEA and Volvo, were mentioned as important actors within in this field, since they have a big influence over smaller suppliers. Some of the auditors mentioned that it can be difficult to motivate firms to engage in DFE activities, since they lack drivers in terms of customer demands. Also, an improved, tougher legislation was brought up as an important driver. Many of the auditors mentioned that a lot of DFE tools are too complicated and resource demanding, especially for smaller firms. Therefore, they requested simpler tools as well as better databases. Other areas mentioned concerned increased environmental training and strengthened motivation.

\footnotetext{
${ }^{21}$ ISO 14001.
} 
A few of the interviewees commented on issues relevant for the debate on the effectiveness of EMS, i.e. whether these systems lead to a better environmental performance or not. These auditors appeared to be convinced that EMS lead to improvements and do not regard the criticism against standardised EMS as justified. Two auditors argued that certified companies have a superior environmental consciousness compared to other firms. One of them specified that they are aware of, and conform with, many legal requirements that many companies not using an EMS are not aware of. He continued by saying that, for example, they greatly improve their handling of chemicals.

\section{Concluding discussion and recommendations}

It is the authors' experience that EMS, without doubt, can be very useful tools from an environmental point of view. However, since many companies, authorities and individuals seem to regard certification according to ISO 14001 as a guarantee for good environmental performance, it is vital to show that companies within a wide spectrum of ambitions and performance can be certified. This means to counterbalance the many success stories that exist, which concern the effects of EMS. Therefore, the discussion within this section is mainly concentrated on weaknesses ${ }^{22}$. This discussion is also intended to function as a good base for recommendations to improve standardised EMS.

The significant environmental aspects are the foundation stones around which EMS are built. Consequently, the environmental effectiveness of these systems to large extent depends on the extent to which products and product-related aspects are classified as significant. The answers relevant for this issue indicated that issues concerning the whole product seldom are judged as significant aspects and sometimes are not considered as environmental aspects at all. This means that attention is seldom paid to product characteristics such as resource demands during the use phase, impacts during the end-of-life phase, recyclability, etc. However, incoming goods and energy appear normally to be among the environmental aspects, which is positive. For instance, a few of the auditors emphasised that companies improve their purchase procedures and handling of chemicals. Nevertheless, many answers also revealed that the requirements posed to suppliers sometimes tend to be very weak; the case appeared even worse concerning information to customers. One important issue clearly is the companies' possibilities to influence. To ensure that the most important flows of materials and energy are included in EMS, the standard requirements, or at least their application, should be altered so that product issues are always regarded as environmental aspects ${ }^{23}$. The assessment of environmental aspects is a more delicate question. It is worrying that product aspects seldom are judged as significant and that some companies are reluctant to assess product aspects as significant. Generally speaking, many important resource flows are clearly connected to the products, which is why, according to the existing standard formulations, they ought to be considered as significant aspects. A problem is that the standard does not, and probably cannot, define the scope of an EMS and inform on how to weight aspects that exist along the life cycle. For example, when assessing a process chemical, one company may consider it as harmless if it does not lead to any toxic emissions at their site. On the other hand, this chemical could cause serious environmental impacts when it is produced or when the manufactured product is disposed of. To conclude, there are many important issues

\footnotetext{
${ }^{22}$ Thus, the whole paper should be read to get a less biased picture of the role of auditors and their opinions.

${ }^{23}$ This applies to manufacturing firms.
} 
that should be discussed and clarified. Obviously, the auditors have clearly different opinions regarding many of these issues.

Concerning the complete EMS, an absolute majority of the interviewees stated that they are focused on a specific facility. This means that a dominant part of the EMS activities and procedures apply to the certified site. To what extent these activities and procedures are based on a life-cycle perspective, and are complemented with EMS parts that are focused on other phases in the life cycle, varies. The auditors' views ranged from allowing a narrow perspective to demanding a more holistic approach. A few of them described a process where companies first focus on their own sites, which includes the legal requirements and often such aspects as emissions, toxic chemicals, risk prevention, waste, and then after a few years can manage to widen the scope. These respondents saw signs of companies reaching this state today, i.e. a stage where they reflect on products and product-related issues as environmental aspects and start to gather and use more information from the life cycle. However, commonly mentioned bottlenecks are complicated tools, difficulties in receiving useful information and lack of resources in terms of staff and competence. An important comment was that legal requirements steer companies towards a site-oriented perspective. It is unfortunate that many EMS seem to have a narrow scope. Since legal requirements and authority control to great extent focus on the facilities, it would be advantageous if EMS could cover a wider perspective. Seen from a societal environmental perspective, many pollution problems related to specific sites (point sources) have been solved or clearly reduced. Instead, environmental impact caused by the consumer market, e.g. in the form of diffuse emissions, stand out as vital. Consequently, from an environmental point of view, EMS covering a wider scope would be preferable and make EMS a more useful tool when striving for a sustainable development.

Focusing on product development, a majority of the auditors require environmental considerations to be included in this process and the remaining part try to influence the companies in that direction through discussions, since they are of the opinion that the standard does not support such requirements. However, how these environmental factors are prioritized in comparison to other factors, e.g. concerning economy and quality, seem to be an issue for the companies. Moreover, the scope of the environmental considerations apparently varies. Some auditors allow a scope dominated by site-specific aspects, while others require a wider perspective. Two of the auditors suggested the interesting idea of extending ISO 14001 with a special section that covers products/product development. This idea seems fruitful and important and could probably solve or reduce many of the problems identified during this study. A product section could include requirements concerning environmental considerations during the product development process. Even if it cannot include specific demands concerning environmental criteria, it could specify that environmental issues must be regarded and that it shall be stated how the different areas in the product development process have been prioritized.

Concerning whether EMS engage the right staff categories having products in mind, many auditors recognise that it is sometimes problematic to involve and motivate product designers regarding the environment. This means that there are many certified enterprises where the EMS do not properly influence the designers, whose decisions to large extent affect the flows of material and energy and thereby the accompanying environmental impacts. As within almost every category of questions, the answers cover a wide range of opinions. Other respondents 
indicated that they require that the right persons are involved and that this is not usually a problem.

The opinions on the meaning of continual improvements vary. About one-half require that some improvements are of an operational character, while one-third approve progress solely of a management type. This means that the auditors disagree regarding how closely connected the improvements should be to direct environmental impacts. The key commitment of continual improvement seems to be weakly linked to products. For instance, environmental targets are seldom directed at products. However, the answers showed that the auditors approve improvements all over the supply chain, which means that the standard and its interpretation do not prevent wider perspectives. The divergence in interpretations, and thereby requirements, suggests that the standard should be clearer on the meaning of environmental performance.

It seems important to emphasise that performance regarding improvements is often calculated as ratios, where for example the amounts of raw materials are divided by profit indicators. The improvements seldom involve total environmental impacts and the companies have great possibilities to influence how performance is calculated. Consequently, deterioration in environmental impacts can be compensated by business improvements. Here again, the standard should be clearer. From a societal perspective, it is crucial to monitor total numbers as well.

About one-half of the auditors do not believe that companies save improvements to ensure future progress, while others admit that this sometimes is the case. These results indicate that EMS normally function as a driver for progress, although mostly facility-oriented progress. Nevertheless, they sometimes block innovations, which seems to be most common at small firms. Therefore, it is important to establish support for small enterprises, which are important actors concerning the environment, to help them to work effectively on environmental issues.

A majority of the respondents classified their possibilities to strengthen the connection between EMS and DFE as great. Only a few of them asked for tougher standard formulations regarding products, while others wanted clarifications rather than stronger requirements. Judging from the impressions and comments, it is a hot issue concerning to what degree auditors are allowed to function as consultants. Many interviewees spontaneously mentioned that they transfer information between companies that are not competing.

To strengthen the connection between EMS and DFE, customer demands seem to be of crucial importance. This includes consumers as well as business customers. Large multinational companies were mentioned as important actors within this field, since they have a big influence over smaller suppliers. Other mentioned areas included better legislation and increased competence and knowledge.

In summary, to strengthen the trustworthiness and environmental effectiveness of standardised EMS, it is vital to strengthen the link to products and product development. To achieve this, the formulations in ISO 14001 should be tougher and clearer. Probably, the trustworthiness of EMS, and thereby also the situation for companies, auditors and the environment, would gain if the product-related requirements were interpreted and handled more equally. Today, standardised EMS in many areas of interest appear to be non-standardised. 
The mentioned factors that influence the use of EMS are mainly within the frames of EMS and their application. In addition, how well EMS and DFE activities can and will be incorporated to large extent depends on many societal factors, e.g. market demands, legislation and the availability of useful tools and information [1]. These external factors have to be emphasised by governments, authorities, the academia and the public in order to strengthen the incentives to implement product-oriented environmental management systems (POEMS).

\section{Acknowledgements}

This research was sponsored by the Swedish Association of Graduate Engineers and The Programme for Production Engineering Education and Research.

\section{References}

[1] Ammenberg J and Sundin E. Products in Environmental Management Systems: Drivers, Barriers and Experiences. Submitted to Journal of Cleaner Production, 2003.

[2] Karlsson M. Green Concurrent Engineering. A Model for DFE Management Programs. Doctoral Dissertation, the International Institute for Industrial Environmental Economics, Lund University, Sweden, September, 2001.

[3] Brezet H, Houtzager B, Overbeeke R, Rocha C and Silvester S. Evaluation of 55 POEM Subsidy Projects. Product Oriented Environmental Management. Delft Technical University, Internal report, August 2000.

[4 ] van Hemel C. Ecodesign Empirically Explored: Design for Environment In Dutch Small and Medium-Sized Enterprises. PhD Thesis: Design for sustainability research programme, Publication no 1: Delft University, The Netherlands, 1998.

[5] Hjelm O, Lundgren J and Idegren L. Miljöledd Produktutveckling. Ett Projekt i

Skärningspunkten mellan Miljöledning och Miljöanpassad Produktutveckling, Slutrapport till NUTEK, Linköping University and IVF, 2001 (in Swedish).

[6] Ries G, Winkler R, and Züst R. Barriers for a Successful Integration of Environmental Aspects in Product Design. Proceedings of “EcoDesign '99”. First international symposium on environmental conscious design and inverse manufacturing, 1999: February 1-3, Tokyo, Japan: 527-32.

[7] ISO World. The Number of ISO14001/EMAS Certification/Registration in the World . January 2002. Internet site: http://www.ecology.or.jp/isoworld/english/analy14k.htm. ISO World. Access: January 13, 2003.

[8] Ammenberg J, Wik G and Hjelm O. Auditing External Environmental Auditors Investigating How ISO 14001 is Interpreted and Applied in Reality. Eco-Management and Auditing, 2001;8:183-92.

[9] Kuhre WL. ISO 14010s Environmental Auditing. Tools and Techniques for Passing or Performing Environmental Audits. PTR Prentice Hall, 1996. ISBN 0-13-380205-1

[10] ISO (International Organization for Standardization). Environmental Management Systems - Specification with Guidance for Use (ISO 14001:1996). Stockholm: Swedish Standards Institution.

[11] European Commission. Official Journal of the European Communities. L 168, vol. 1, no. 
1836/93, July 10, 1993.

[12] ISO (International Organization for Standardization). Environmental Management Systems - General Guidelines on Principles, Systems and Supporting Techniques (ISO 14004:1996). Stockholm: Swedish Standards Institution.

[13] ISO (International Organization for Standardization). Environmental Management Environmental Performance Evaluation - Guidelines (ISO EN 14031:1999). Stockholm: Swedish Standards Institution.

[14] Ayres RU. Industrial Metabolism: Theory and Policy. In: Ayres RU and Simonis UE, editors. Industrial Metabolism - Restructuring for Sustainable Development. Tokyo: United Nations University, 1994:3-20.

[15] Berkhout, F. Aggregate Resource Efficiency. Are Radical Improvements Impossible? In: Vellinga P, Berkhout F and Gupta J., editors. Managing a Material World. Perspectives in Industrial Ecology. Kluwer Academic Publishers, 1998: 165-89.

[16] Halvorsen K. Samhällsvetenskaplig metod (Translated: Methodology for Social Science), Lund: Studentlitteratur, 1992.

[17] Kvale S. Interviews. CA, Thousand Oaks: SAGE Publications, 1996.

[18] Ammenberg, J. How do Standardised Environmental Management Systems Affect Environmental Performance and Business? Licentiate thesis no. 907. ISBN 91-7373-124-2. Environmental Technique and Management. Linköping University, 2001.

[19] Klinkers L, van der Kooy W and Wijnen H. Product-oriented Environmental Management Provides New Opportunities and Directions for Speeding Up Environmental Performance. Greener Management International, summer 1999: 91-108.

[20] van Berkel R, van Kampen M and Kortman J. Opportunities and Constraints for ProductOriented Environmental Management Systems (P-EMS). Journal of Cleaner Production, 1999;7:447-55.

[21] WBCSD (World Business Council for Sustainable Development). Eco-Efficiency. Creating More Value with Less Impact. Switzerland, 2000.

[22] Schmidheiny S. Changing Course. WBCSD (World Business Council for Sustainable Development), Switzerland: MIT Press, 1992. 